\title{
Erratum to: Prevalence of Helicobacter pylori Infection Worldwide: A Systematic Review of Studies with National Coverage
}

\author{
Bárbara Peleteiro $^{1,2} \cdot$ Ana Bastos $^{2} \cdot$ Ana Ferro $^{2} \cdot$ Nuno Lunet $^{1,2}$
}

Published online: 10 July 2015

(c) Springer Science+Business Media New York 2015

\section{Erratum to: Dig Dis Sci (2014) 59:1698-1709 \\ DOI 10.1007/s10620-014-3063-0}

The authors of the article 10.1007/s10620-014-3063-0 in DDAS did not report their funding source accurately. This erratum is published to correctly cite the funding source. The acknowledgement section should read as:

Acknowledgments The authors gratefully acknowledge the collaboration of Bruno Barroso and Helena Carreira for the participation in the screening of reference lists and data extraction. This work was supported by "Fundo Europeu de Desenvolvimento Regional" (FEDER) funds through the "Programa Operacional Factores de Competitividade" (POFC)—COMPETE (FCOMP-01-0124-FEDER021181) and by national funds through the "Fundação para a Ciência e a Tecnologia" (PTDC/SAU-EPI/122460/2010 and SFRH/BPD/ 75918/2011).

The online version of the original article can be found under doi:10.1007/s10620-014-3063-0.

Bárbara Peleteiro

barbarap@med.up.pt; barbarapeleteiro@gmail.com

1 Department of Clinical Epidemiology, Predictive Medicine and Public Health, University of Porto Medical School, Al. Prof. Hernâni Monteiro, 4200-319 Porto, Portugal

2 Institute of Public Health of the University of Porto (ISPUP), Porto, Portugal 